\title{
HACKEO URBANO:
}

PRÁCTICAS ARTÍSTICAS

PARA UNA MEDIACIÓN

EDUCATIVA Y

CIUDADANÍA

PRO-ACTIVA

\section{URBAN HACKING: ARTISTIC PRACTICES FOR EDUCATIONAL MEDIATION AND PRO-ACTIVE CITIZENSHIP}

\section{Juan Francisco Fuentes-Lojo}

Arquitecto por la Universidad Ramón Llull

Máster en Comunicación Arquitectónica por la Universidad Politécnica de Madrid

(D) https://orcid.org/0000-0002-0743-2493

\section{Resumen}

Los entornos urbanos de las grandes urbes, muchas veces son diseñados desde las organizaciones ajenas a los individuos, su memoria, sus vivencias y sus desigualdades. La trama urbana resultante acaba siendo un tejido discontinuo, por el que nos movemos entre diferentes nodos, empobreciendo los espacios intermedios; es decir, las fricciones que se producen en el espacio público.

Frente a este tipo de desarrollo se detectan iniciativas artísticas, que serán estudiadas en el transcurso de este artículo, en las que los ciudadanos adquieren un rol activo en la producción de ciudad a través de la generación o re-configuración de espacios urbanos. Los instrumentos artísticos de esta metodología consisten en micro-acciones con un enfoque participativo; experimental y educativo, que permiten imaginar una nueva ciudad y sus posibilidades. De este modo, podemos entender estas prácticas como hackeo urbano, donde el término hackear se refiere al hecho de transformar e intervenir en el código de la ciudad, para poder cumplir nuevos objetivos.

\section{Palabras clave}

Espacio público; mediación educativa; transformación urbana; participación ciudadana

\begin{abstract}
Urban environments in large cities are often designed by organizations disconnected to people, their memory, experiences and inequalities. The resulting urban pattern ends up being a discontinuous layout, through which we move between different nodes, impoverishing the intermediate spaces; in other words, the frictions that occur in public space.

Against this kind of development, many artistic initiatives are detected and will be studied in the course of this article, in which citizens acquire an active role in the city through the generation or reconfiguration of urban spaces. The artistic tools of this methodology are made up of micro-actions with a participatory approach; experimental and educational. It seems that they are the ones who allow us to imagine a new city and its possibilities. We would therefore understand these practices as urban hacking, where hacking refers to the fact of transforming and intervening the city code, in order to achieve new goals.
\end{abstract}

\section{Key words}

Public space; educational mediation; urban transformation; citizen participation. 


\section{INTRODUCCIÓN}

Este artículo es una síntesis de una investigación previa: "Hackeo Urbano: catálogo de prácticas arquitectónicas por una ciudadanía pro-activa"1, basada en el desarrollo del propio concepto Hackeo Urbano, para designar una tipología de práctica artística detectada en el espacio urbano de nuestras ciudades. A la hora de trabajar con la noción de hackeo urbano, podemos determinar dos líneas de intervención atendiendo a dos criterios: acciones de participación y objetos de activación sociocultural.

Para contextualizar este tipo de proyectos, así como la trascendencia que tiene el concepto de hackeo urbano en la actualidad, hay que indicar que sus antecedentes surgen en 2008. Tras la crisis económica, que provocó una parálisis urbanística y una burbuja inmobiliaria, es el momento en que la práctica arquitectónica deja de centrarse en el diseño y construcción de edificios para normalizar nuevos territorios de acción, que van más allá del objeto físico y son materializados en distintas disciplinas artísticas, culturales y pedagógicas (Baraona, 2011). Si la ya pasada época de abundancia económica dio lugar a desarrollos burocratizados y excesivos, a un momento de escasez, como el actual, le corresponderán actuaciones más contenidas, pero también más abiertas al juego espontáneo de sus habitantes.
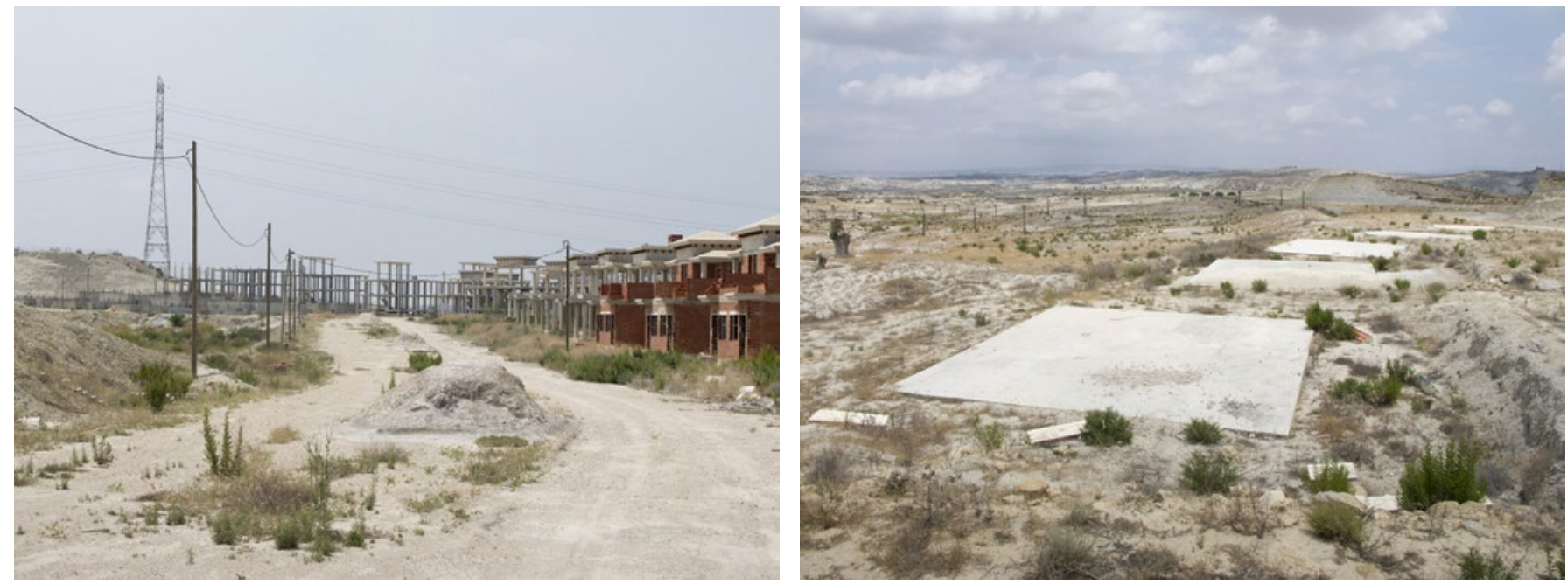

Imágenes 1 y 2. Imágenes de Ruinas Modernas, una topografía del lucro, de Julia Schulz-Dornburg. Un inventario fotográfico de la construcción especulativa en España. En él, se retratan parajes ocupados por urbanizaciones abandonadas; paisajes residuo que muestran la herencia en el territorio del estallido de la burbuja inmobiliaria. Fuente: https://www.metalocus.es/en/news/ruinas-modernas-una-topograf\%C3\%ADa-de-lucro-modern-ruins-topography-lucre

Las rígidas estructuras de actuación y de pensamiento por parte de las administraciones, como son los planeamientos generales o los métodos de toma de decisiones top-down ${ }^{2}$, intensifican la desoladora situación urbana actual. En los últimos años, se pone en juego la búsqueda intensificada de los espacios públicos y propuestas de planificación alternativa, para dar respuesta a los vacíos urbanos derivados de la crisis anteriormente comentada (Di Siena, 2009). Por ello, se deben potenciar nuevas formas de intervención urbana que incorporen tendencias naturales, ocupaciones informales y actuaciones no permanentes que puedan crear oportunidades para los espacios degradados y abandonados y los residuos que la propia ciudad genera al margen la producción mercantil (Lefebvre, 1968). 
Avanzando en estas ideas, tomemos como ejemplo las prácticas que se aplican en la Escuela de Arquitectura de Alicante (Calvillo y Mesa, 2018). Concretamente en la asignatura de proyectos de los años 2010 a 2013, se pusieron en práctica pedagogías muy concretas que tratan de cambiar la percepción del alumnado sobre la práctica arquitectónica. En ellas se designaba la arquitectura como "prótesis": de escasa materialidad, ensamblajes de elementos ya existentes como método de intervención que, al ser instaladas multiplican las opciones y articulan coexistencias conflictivas sin neutralizarlas. A raíz de esta reflexión, se pone en valor el poder de las "micro-acciones" a modo de acupuntura urbana, de enfoque participativo, educativo y experimental que imaginan una nueva ciudad y sus posibilidades (Mesías-Lema, 2019). Esto nos permite volver a las visiones de los situacionistas, para recuperar y educar al habitante activo, que se acerca a la ciudad de forma más lúdica, dinámica, efímera y sostenible; dándole un uso más recreativo e intensivo al espacio urbano (Jacobs, 1961).
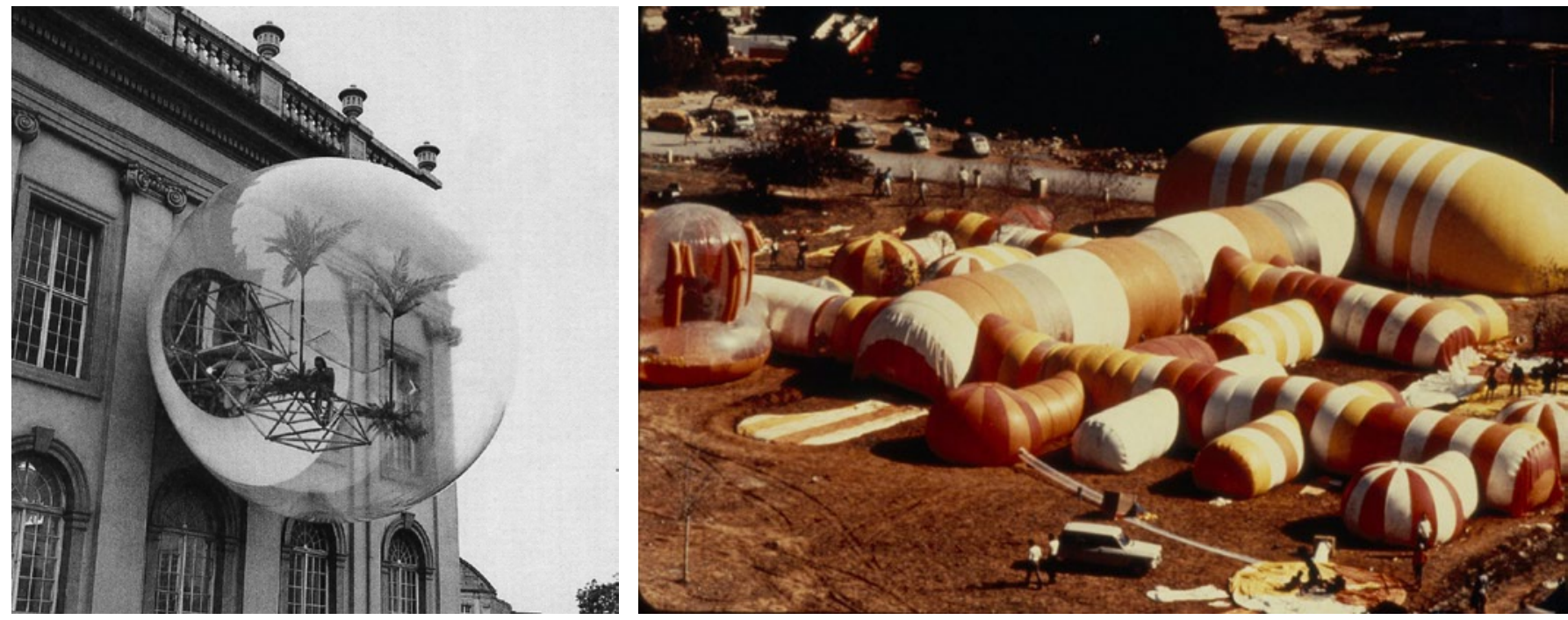

Imagen 3. Instalación Oasis No. 7, de 1972 por el grupo vienés Haus-Rucker-Co, en Alemania. Intentando motivar al espectador a que se vuelva un ciudadano activo, diseñan una burbuja que de diámetro, constituía un espacio lúdico, casi una reserva natural dentro del entorno urbano, un paraíso de palmeras dentro de la ciudad. Fuente: https://www.eldia.es/cultura/2020/04/04/mira-

da-medio-plazo-22429722.html

magen 4. En 1971, José Miguel Prada Poole levantó en el Port de Sant Miquel (Ibiza) la Instant City, una ciudad efímera de autoconstrucción colaborativa, formada por módulos de PVC sostenidos por flujo de aire. Fue la actividad más impactante del VII Congreso del International Council of Societies of Industrial Design (ICSID). Fuente: https://www.jotdown.es/2013/08/construir-castillos-con-el-aie-la-ciudad-instantanea-de-ibiza

Hace ya algunos años que, debido al auge de la cultura de la participación ciudadana, están apareciendo nuevas estrategias urbanas, llamadas P2P³ (Freire, 2009). Estas nuevas formas de hacer ciudad, cuentan con agentes, metodologías y objetivos muy diferentes a los tradicionales.

En este nuevo urbanismo participativo surgen una serie de iniciativas en las que los ciudadanos adquieren un rol activo en la producción de ciudad a través de la generación o reconfiguración de espacios urbanos que habitan (Nebot, 2014). En este sentido, la participación ciudadana surge como motor del proceso, pero entendida no solo como debate y deliberación, sino especialmente como acción directa en la "construcción" de la ciudad (Freire, 2009).

En España se han instaurado diversos colectivos, desde hace años, que se dan a conocer como 'Recetas Urbanas' (http://www.recetasurbanas.net), 'Straddle3' (https://straddle3.net), 'Caldo de cultivo' (http://caldodecultivo.com), 'Esto no es un solar' (https:// estonoesunsolar.wordpress.com), etc. Ellos han hecho brotar, del vacío legal y de la 
cesión temporal de solares, una práctica artística más optimista que cambia las reglas del juego (Trachana, 2013). Solares vacíos, construcciones temporales, participación ciudadana, planes de empleo, mediación y educación y nuevas lógicas permiten introducir el concepto de Hackeo Urbano en la práctica artística.
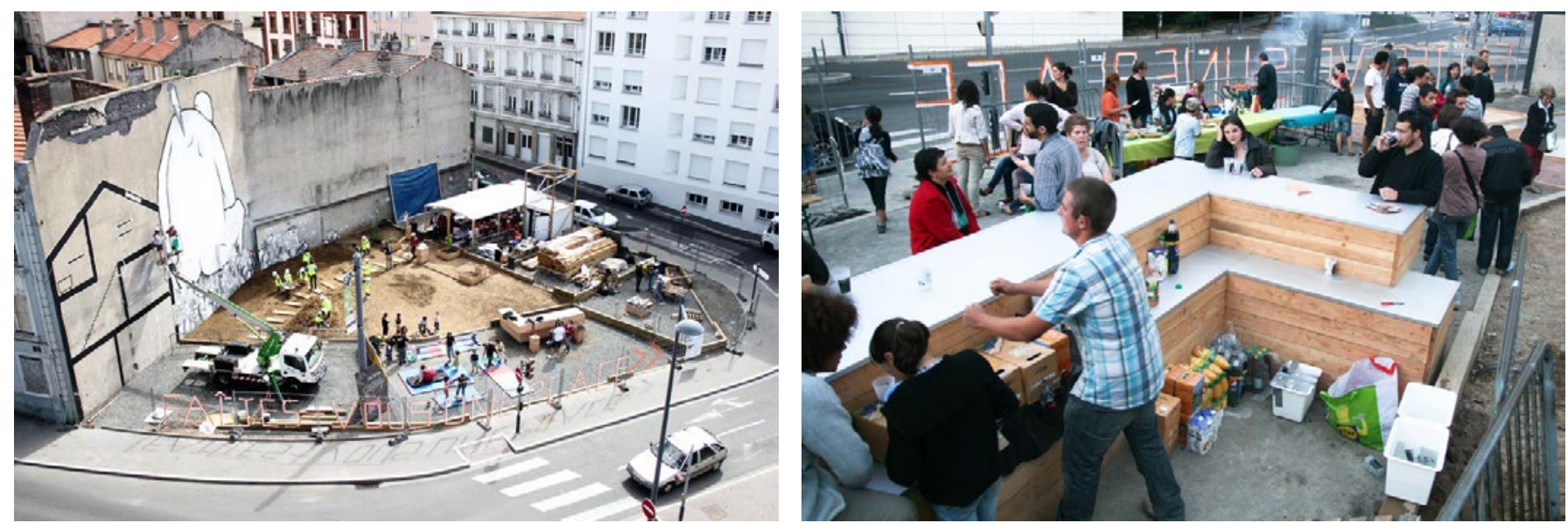

Imágenes 5 y 6. Place au change es un proyecto colaborativo desarrollado en 2011 en un solar abandonado de Saint-Étienne, en Francia. Este ejemplo de hackeo urbano se basó en la colaboración ciudadana para crear un espacio público durante 4 semanas en el que se realizaron talleres de carpintería para fabricar el mobiliario, así como conciertos y espectáculos. Fuente: http://www.collectifetc.com/realisation/place-au-changement-opus-2/
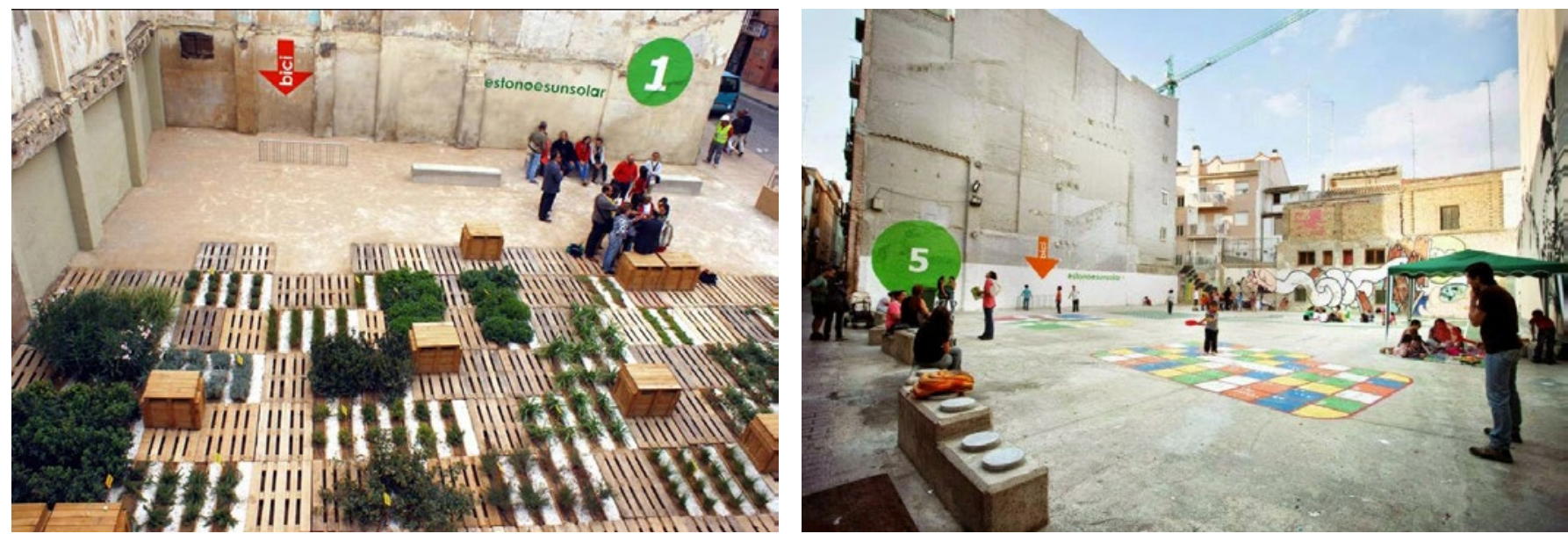

Imágenes 7 y 8. Patrizia Di Monte e Ignacio Grávalos han recorrido Zaragoza con su proyecto estonoesunsolar, ejecutando 29 intervenciones entre 2009 y 2010 , logrando equilibrar la ciudad a través del reciclaje de más de $42.000 \mathrm{~m} 2$ de superficie en desuso en espacios públicos. Fuente: https://www.plataformaarquitectura.cl/cl/02-349303/ esto-no-es-un-solar-reconvirtiendo-parcelas-vacias-en-espacio-publico-parte-ii

\section{HACKEO URBANO COMO PRÁCTICA ARTÍSTICA SENSIBLE}

El término "Hackear"4 se refiere a la acción de explorar e introducir alteraciones en un código o un dispositivo (Bartlebooth, 2016). Según el imaginario colectivo, el hacker es quien se infiltra sin permiso en sistemas informáticos quebrantando sus mecanismos de seguridad para alterar de manera ilícita y malintencionada su funcionamiento (Fossatti, 2011). Pese a ello, el programador estadounidense Richard Stallman, fundador del software libre, defiende que no debemos confundir la figura del hacker con un delincuente informático. Fueron los medios de comunicación, cuando descubrieron a los hackers en los años 80, los que decidieron señalar únicamente su faceta más controvertida e ilegal. Si bien es cierto que algunos de ellos se han dedicado al sabotaje de redes y robo o destrucción de información, son llamados crackers por el resto de la comunidad para que queden perfectamente diferenciados (Himanen, 2002). 
El hecho de analizar con precisión cada objeto, cada sistema, permite entender las lógicas y mecanismos que lo hacen funcionar para, una vez asimilados, proponer usos alternativos, nuevos y no previstos (Baraona y González, 2013). De este modo, ¿puede este concepto tener aplicaciones positivas en el campo artístico aplicado al entorno urbano como mediación educativa?

¿Qué tiene de hacker John Cage en su controvertida "pieza musical" 4'33?... Es más una reflexión o una mirada diferente de la realidad que una composición musical al uso. O la cantante estadounidense Lady Gaga, que usó un vestido hecho con auténtica carne de ternera en la entrega de unos conocidos premios musicales: ¿se trata de un hackeo al esteoreotipado mundo de la moda o es simplemente una provocación? La artista se defendía: "soy algo más que un trozo de carne". Otro caso curioso lo encontramos en la DRM Chair, la particularidad de esta pieza de mobiliario, diseñada por los suizos Les Sugus, es que solo permite que te sientes en ella ocho veces, luego se autodestruirá, gracias a un sistema de Arduino que detecta al usuario. ¿Es un hackeo a la industria del diseño y su obsolescencia programada o una alegoría para entender los sistemas restrictivos y el software propietario?

Todas estas actividades tienen en común la diversión, la inteligencia, la exploración y la pasión por el campo que las ocupa. Por tanto, son las que muestran una inteligencia lúdica, las que poseen un "valor de hackeo".

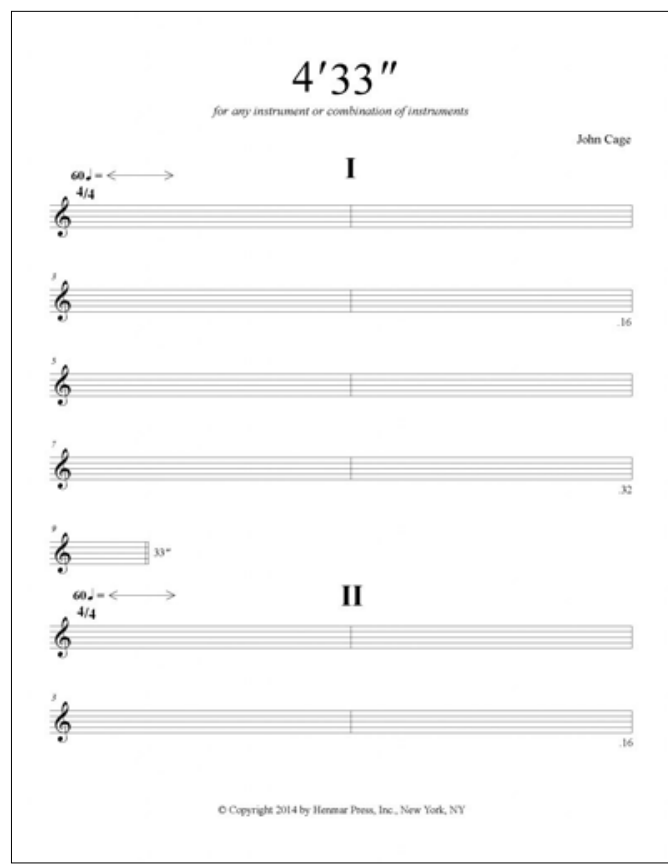

Imagen 9. partitura de 4'33"; una obra musical en tres movimientos realizada por el compositor estadounidense John Cage en 1952. En ella se indica al intérprete que ha de guardar silen cio y no tocar su instrumento durante cuatro minutos y treinta y tres segundos, para poder escuchar todos los sonidos que normalmente son enmudecidos por la obra en sí, como el paso de las hojas, los sonidos emitidos por el público, etc. Fuente: https://salamancartvaldia.es/not/149426/n-4-33-de-john-cage/

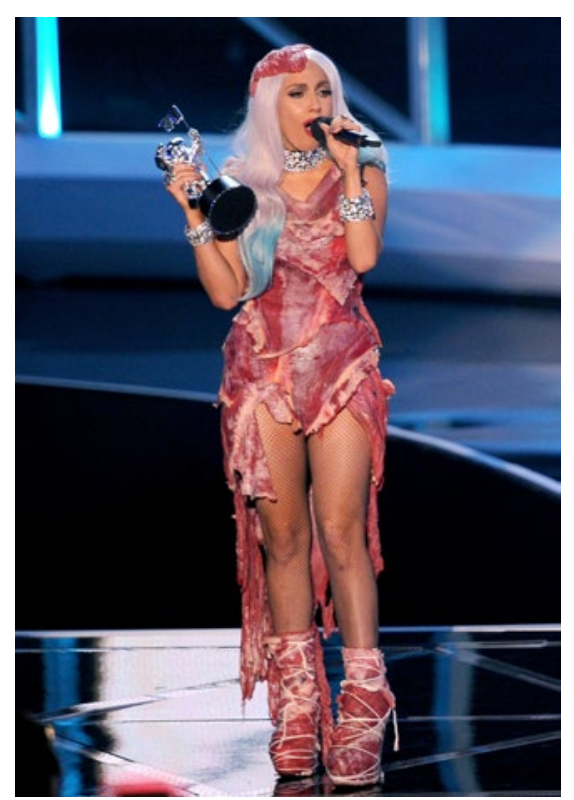

Imagen 10. La artista Lady Gaga en los MTV Video Music Awards, en el año 2010. Fuente: htto://www. aeromental.com/2010/09/13/el-vestido-de-carnede-lady-gaga-en-los-premios-mtv-vma-2010/

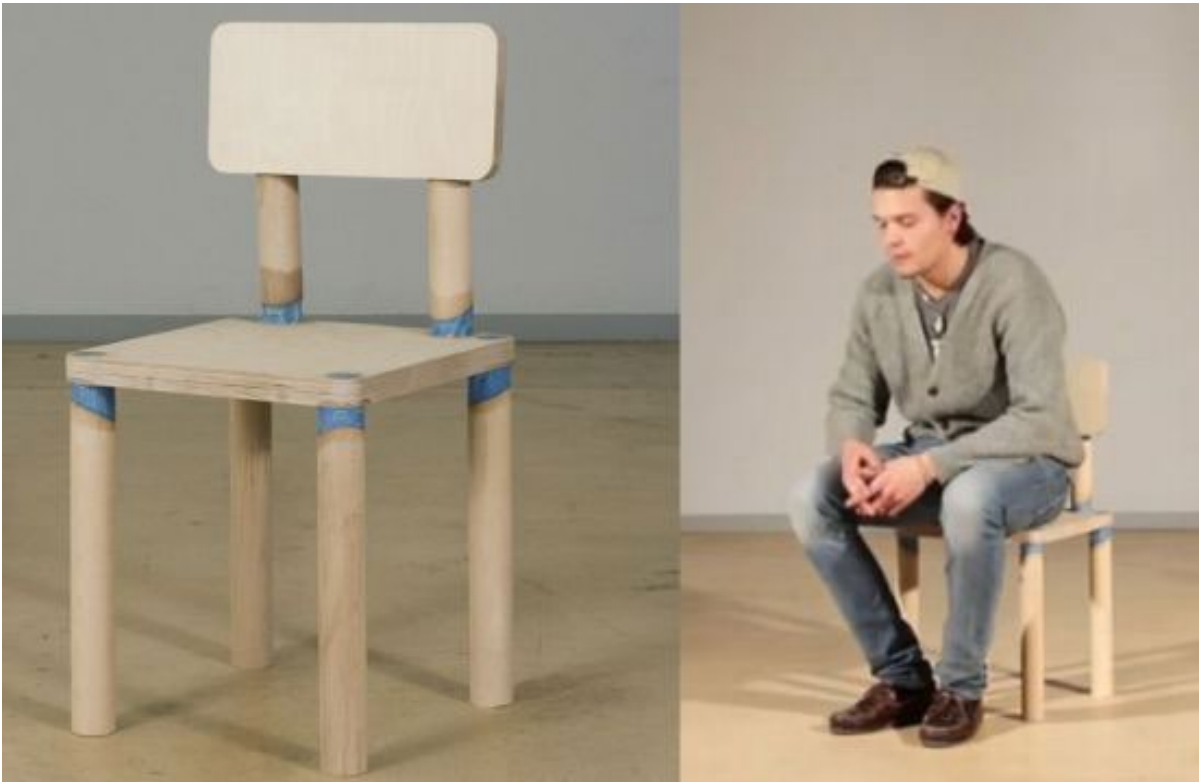

Imágenes 11 y 12. DRM chair 2013 (la silla del software propietario). Fuente: https://vimeo.com/60475086

La ciudad, el territorio, las calles o una comunidad de vecinos pueden ser entendidos también como códigos a ser modificados y variados, permitiéndonos introducir ciertos grados de informalidad y disidencia (Himanen, 2002). Para ello debemos conocer su lenguaje de programación, su extensión y cómo introducir variaciones en él para transformar el original. De este modo, más que intervenir en el código de la ciudad, interferimos para poder cumplir nuevos objetivos. 
Existen muchas aplicaciones positivas en el hecho de hackear aplicado al entorno urbano: se puede resignificar visualmente la arquitectura, rehabilitar espacios abandonados, mejorar/expandir las funciones de los objetos públicos y privados, generar eventos públicos inesperados, señalar espacios a los que comúnmente no prestamos atención, transgredir barreras urbanas arbitrarias... Podemos afirmar entonces que "hackeo urbano" es la utilidad concreta en el imaginario hacker, que hace referencia a la actividad creativa y constructiva que se vale de acciones planificadas de abajo hacia arriba, orientadas a producir ciudades sostenibles y vivibles a la medida de las personas que las habitan (Fossatti, 2011).
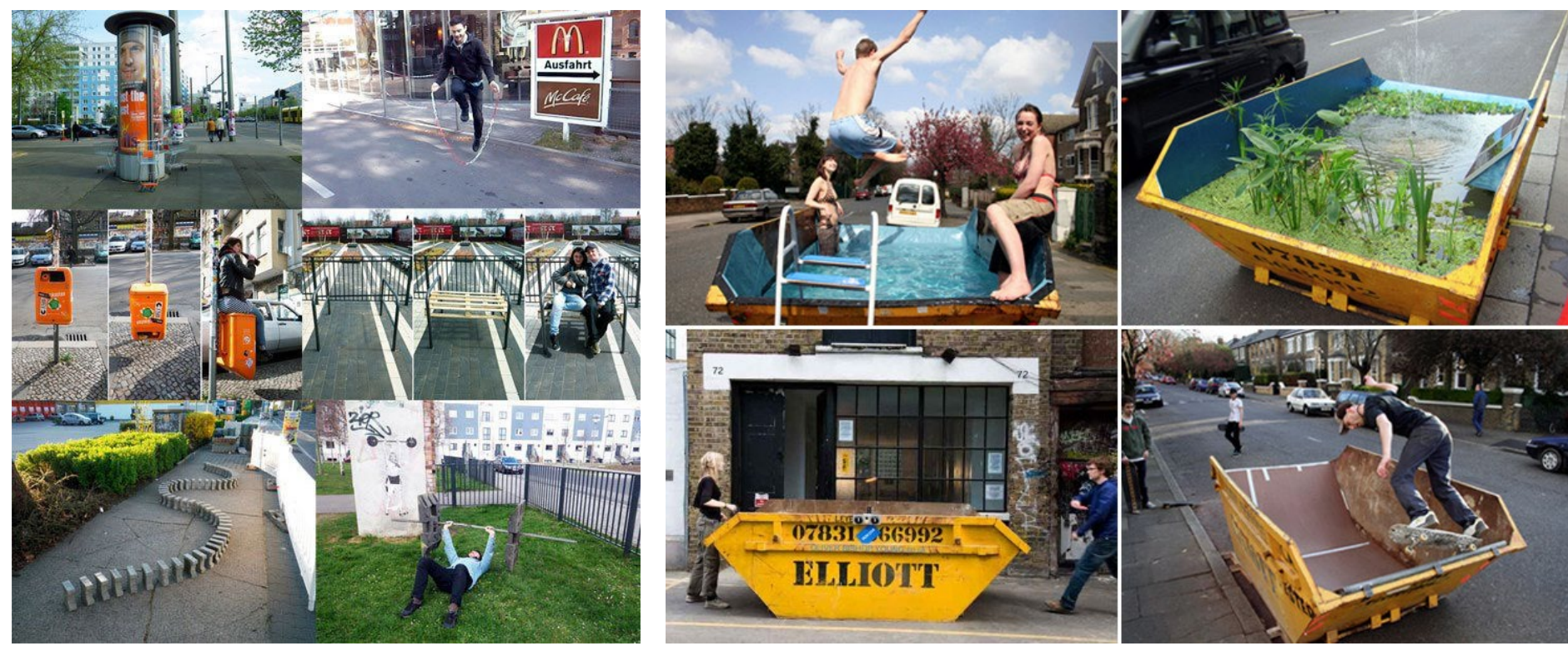

Imágenes 13 y 14. Obras urbanas del artista urbano y activista francés Florian Rieviere. Fuente: https://cfye.com/florian-riviere-urban-hacktivist-6088

Una vez definido el alcance que tiene el concepto propuesto, la investigación avanza mostrando ejemplos que cumplen la definición teórica del término. Estudiaremos todas esas prácticas y micro-acciones que se producen en los entornos urbanos de uso público y que propician la apropiación de dicho espacio por parte de la ciudadanía, transformándolo para que cumpla otras funcionalidades.

De este modo, al empezar a estudiar, los casos se vio la necesidad de puntualizar ciertas diferencias, desglosadas en dos grupos diferenciados que responden a la esencia del proyecto: prácticas activistas asociadas al propio término de hackeo, que tiene que ver con la performance por un lado, y por otro objetos físicos diseñados para que cumplan unas funcionalidades concretas.

\subsection{Acciones de participación ciudadana}

Además de las propias iniciativas ciudadanas que contribuyen a construir un modelo emergente de urbanismo, la política y, especialmente, los gobiernos locales pueden contribuir a generar las condiciones para que surjan estas dinámicas. No se trata ya de seleccionar y diseñar proyectos específicos, sino de acondicionar escenarios para la participación y educación ciudadana en los espacios públicos. De este modo, son imprescindibles estrategias para el empoderamiento ciudadano y que provoquen la apropiación de la tecnología y la información (Freire, 2009). Aun así, no basta únicamente con dar lugar a espacios para la participación. Es importante que recuperemos la tradición de la filosofía situacionista que reconoce al habitante activo que, lejos de permanecer pasivo ante el mundo, puede imaginar su vida; esto es, crearla y recrearla (Trachana, 2013). 


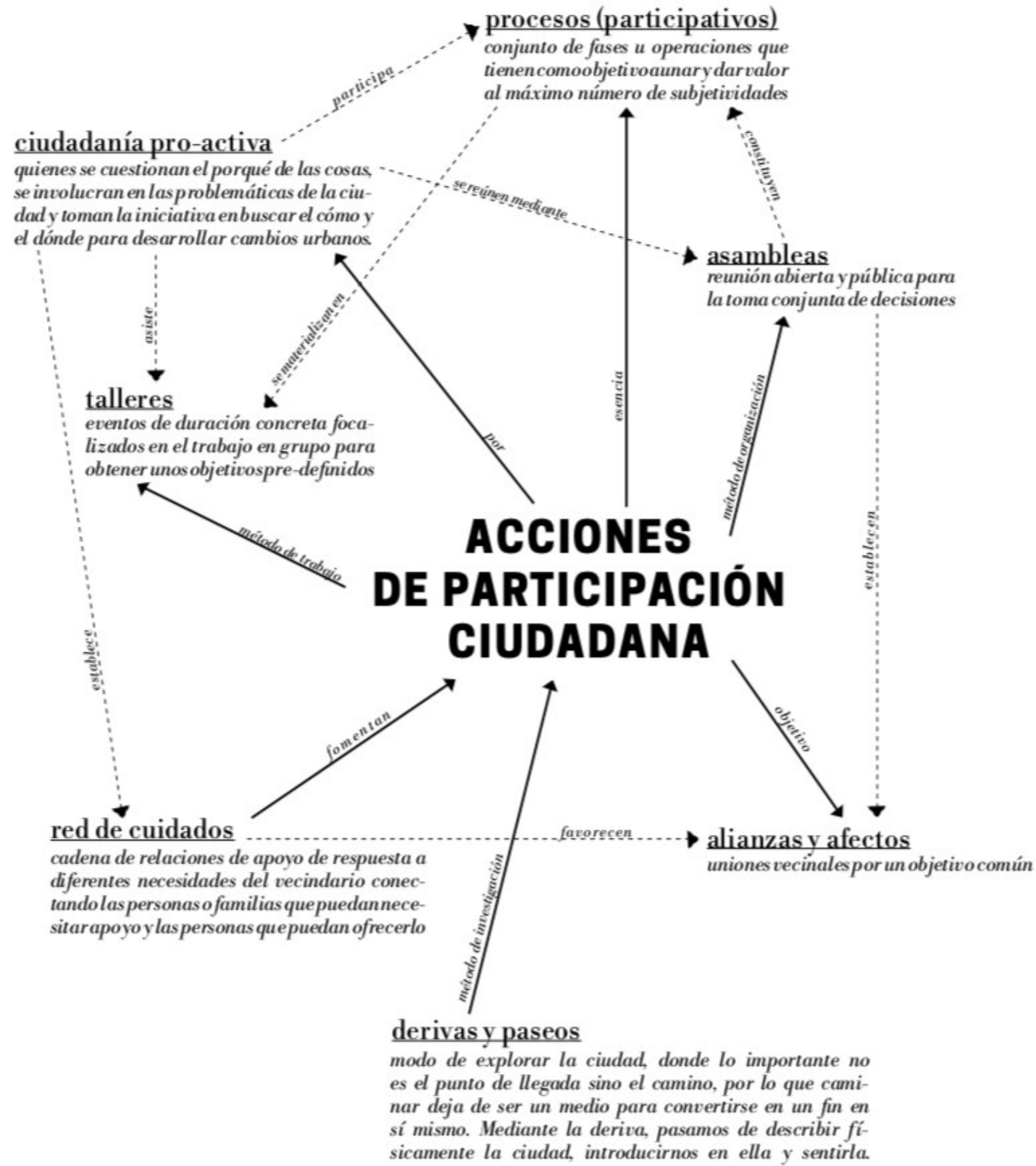

Imagen 15. Esquema explicativo de los conceptos y relaciones que se establecen en la categoría de proyectos denominados como "acciones de participación ciudadana". Fuente: elaboración propia. 
Se muestran a continuación cuatro ejemplos de prácticas artísticas que facilitan la creación de espacios de participación, además de ser desarrolladas de manera colectiva por la ciudadanía pro-activa:

El primero de ellos, el proyecto El Beso, se basa en una propuesta de arte público y ciberfeminismo que cultiva el cuidado y generación de comunidad en torno al barrio de Bellas Vistas. También supone una resignificación simbólica de la calle Topete y sus memorias (cartográficas y afectivas); todo ello gracias a la participación de sus vecinas y vecinos, con especial atención a las primeras, en un proyecto de creación comunitaria analógico y virtual.
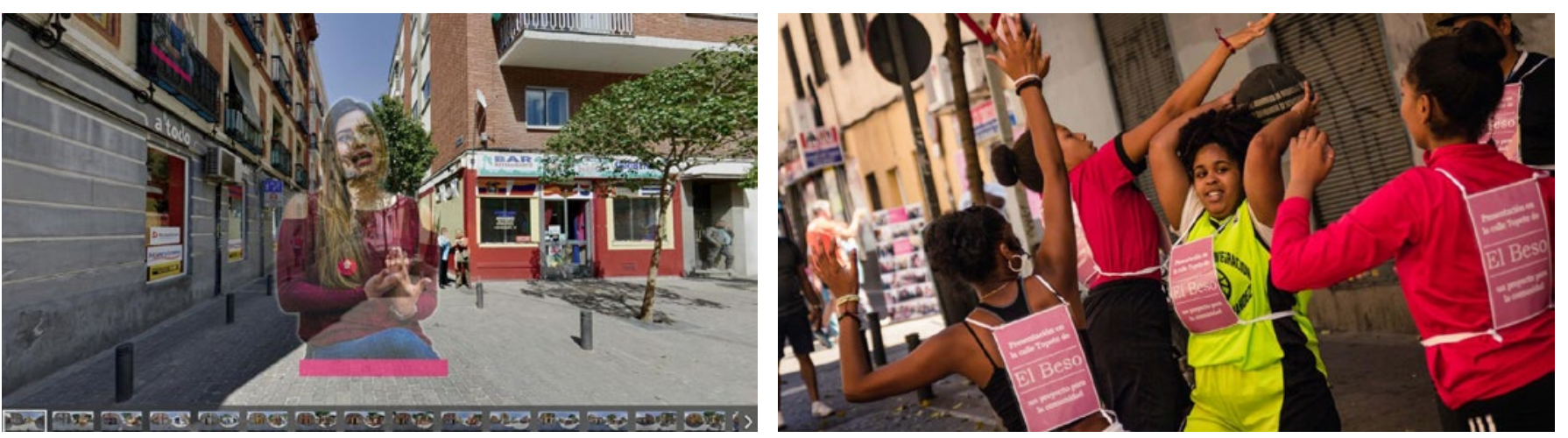

Imágenes 16 y 17. Imágenes de El Beso, de Toxic Lesbinan (2018, Madrid). Fuente: https://www.toxiclesbian.org/proyectos-de-arte-publico-y-ciberfeminismo/el-beso/

De este modo, el valor añadido del proyecto reside en el potencial de las dinámicas de mediación social en la creación de nuevas redes de cuidados entre vecinos del barrio.

En el segundo caso, Cadires a la Rambla, se trata de un lugar de encuentro entre vecinos y visitantes en un momento de remodelación y dinamización de un espacio público tan emblemático como son las Ramblas de Barcelona. La iniciativa se lleva desarrollando desde 1991 y coloniza la calle con más de 150 dispositivos de madera diseñados por los alumnos.

Aun así, esta acción va más allá del diseño formal de las sillas por parte de los alumnos. La bondad de este proyecto reside en la capacidad de crear un espacio de diálogo y participación de manera crítica y reinvindicativa, para tratar las problemáticas actuales de la ciudad.
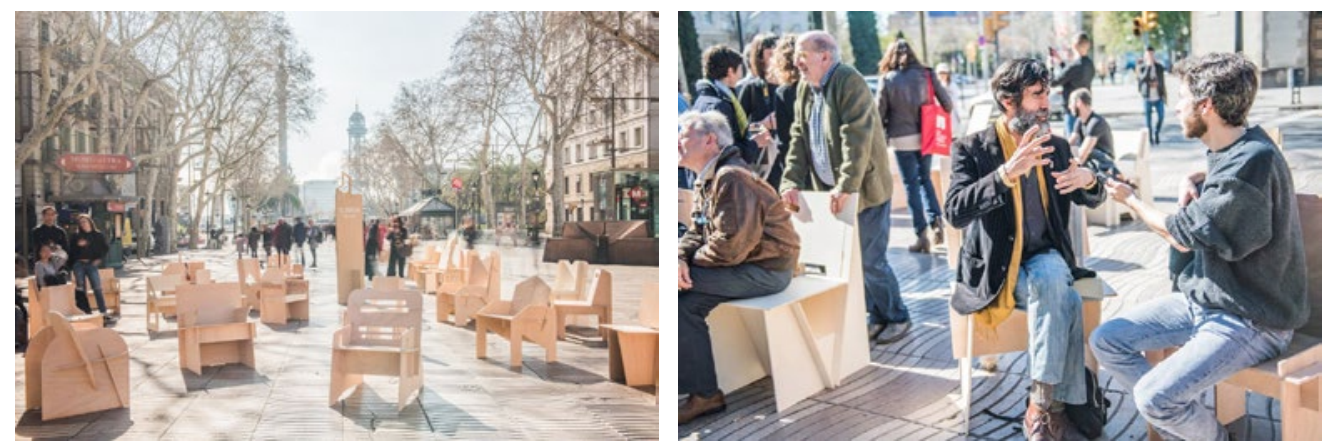

Imágenes 18 y 19. Imágenes de Cadires a la Rambla, por los alumnos del Grado de Diseño de la Universidad Elisava y Go! Acció cultural (2019. Barcelona). Fuente: https://beteve.cat/cultura/rambla-elisava-cadires-2019/

Otro proyecto interesante desarrollado en la Universidad de Diseño Elisava, por alumnos del Máster de Arquitectura Efímera, es VORA. Constituye un límite seguro entre los coches y los usuarios de los nuevos espacios peatonalizados para promover actividades al aire libre, como ocio, lectivas y culturales, en tiempos de coronavirus. 
De este modo, este diseño permite ocupar el espacio público dándole un uso concreto y además su cualidad efímera le permite adaptarse a las necesidades del momento; en este caso, posibilitar dar clases al aire libre y reducir así los riesgos de contagio causados por la pandemia.
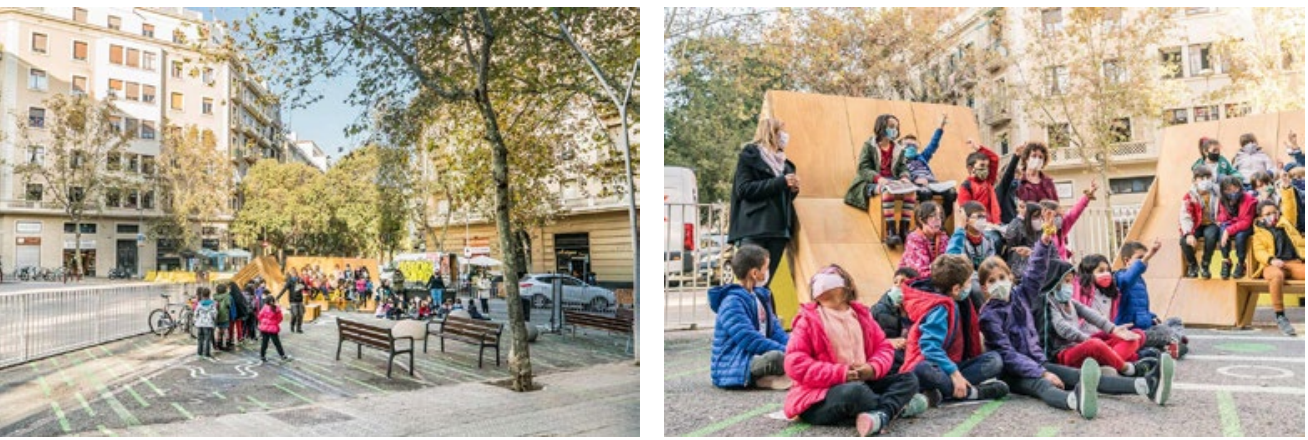

Imágenes 20 y 21. Imágenes de Vora, un prototipo de mobiliario diseñado por los alumnos del Máster de Arquitectura Efímera de la Universidad Elisava (2020. Barcelona). Fuente: https://www.elisava.net/es/noticias/el-prototipo-de-mobiliario-efimero-vora-consolida-el-espacio-ganado-la-calzada-en-tiempos

El último caso de esta categoría, El Templete Fantástico, se basa en un programa piloto de acciones colaborativas en torno al Templete dedicado al cantaor José Menese, en Puerta del Ángel. A lo largo de cuatro meses se realizaron una serie de acciones artísticas abiertas, gratuitas y aptas para todos los públicos (siete en total, en las que hubo baile, música, comida, dinamización con estructuras neumáticas y magia).

Este proyecto es interesante y forma parte de esta investigación por el hecho de resignificar un elemento urbano e icónico para el barrio, mediante acciones participativas. Al final, el diseño de estas actividades tiene una finalidad que va más allá de lo lúdico. Permite transformar un espacio en desuso a la vez que se recupera para el disfrute de los vecinos.
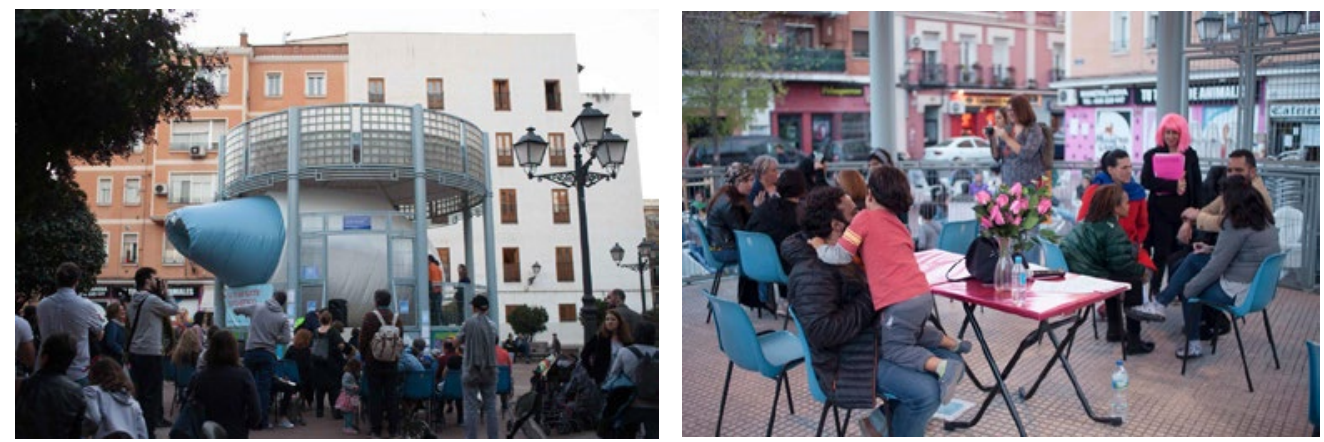

Imágenes 22 y 23. Imágenes de El Templete Fantástico, de Grigri Projects, con intervenciones de Enorme Studio, Colectivo Mico, Paula Valero, Javier Tejera de Bat Spain, Cocinar Madrid, la Big Band de la Complutense y La Mina Films. Colaboración especial de los alumnos del Máster de Efímeras de la ETSAM (2019. Madrid). Fuente: https://grigriprojects.org/procesos/ templetel

En estos ejemplos se entiende el hecho de mediar como un proceso educativo que permite emprender nuevos diálogos, actuando como "puente" entre diferentes actividades, reconstruyendo la relación entre las partes y resolviendo conflictos. Es decir, la principal virtud del hackeo urbano como elemento mediador es el hecho de promover nuevas vías de comunicación con la ciudadanía y poner a su alcance la práctica artística como herramienta de expresión y apropiación del espacio urbano.

No se trata de convencer a nadie de un discurso concreto, se trata de activar su curiosidad, de educar ampliando las formas de conocimiento, y de reflexionar sobre lo vivido con una visión crítica: acercar, educar, participar y cuestionar. Se incentiva la participación de la ciudadanía, fomentando una mediación activa de doble dirección, en la que se aprende a escuchar los intereses de la sociedad, generando un diálogo abierto, continuo y de mejora. 


\subsection{Objetos de activación socio-cultural}

El espacio público se ha reducido, en muchas ocasiones, a lugares de paso y tránsito: parques, plazas, calles, centros culturales, paseos, bajo-puentes... han perdido su esencia como tal. La privatización y legalización los han ido despojando de sus cualidades originales, han dejado de ser espacios públicos de uso común, al no funcionar como instrumentos para activar el sentido colectivo.

Es por ello que las prácticas artísticas aquí estudiadas se entienden como una herramienta distanciada de las grandes obras de arquitectura o ingeniería y son más próximas a las redes que posibilitan formas de vida (Calvillo y Mesa, 2018). Se podría decir que la práctica artística debe ser una herramienta que permita imaginar lo inimaginable, es decir, herramientas abiertas a su reconfiguración y reutilización; que permitan construir problemáticas que no estaban previstas; que sean tecnologías de la aspiración que nos permitan expandir el horizonte de nuevas expectativas urbanas (Estaella, 2016). De este modo, estos utillajes deben permitir experimentar en la ciudad para dar lugar a nuevas naturalezas urbanas llamando a la participación, pero sin diseñar lo que debe ocurrir en un lugar determinado ni en un tiempo concreto.

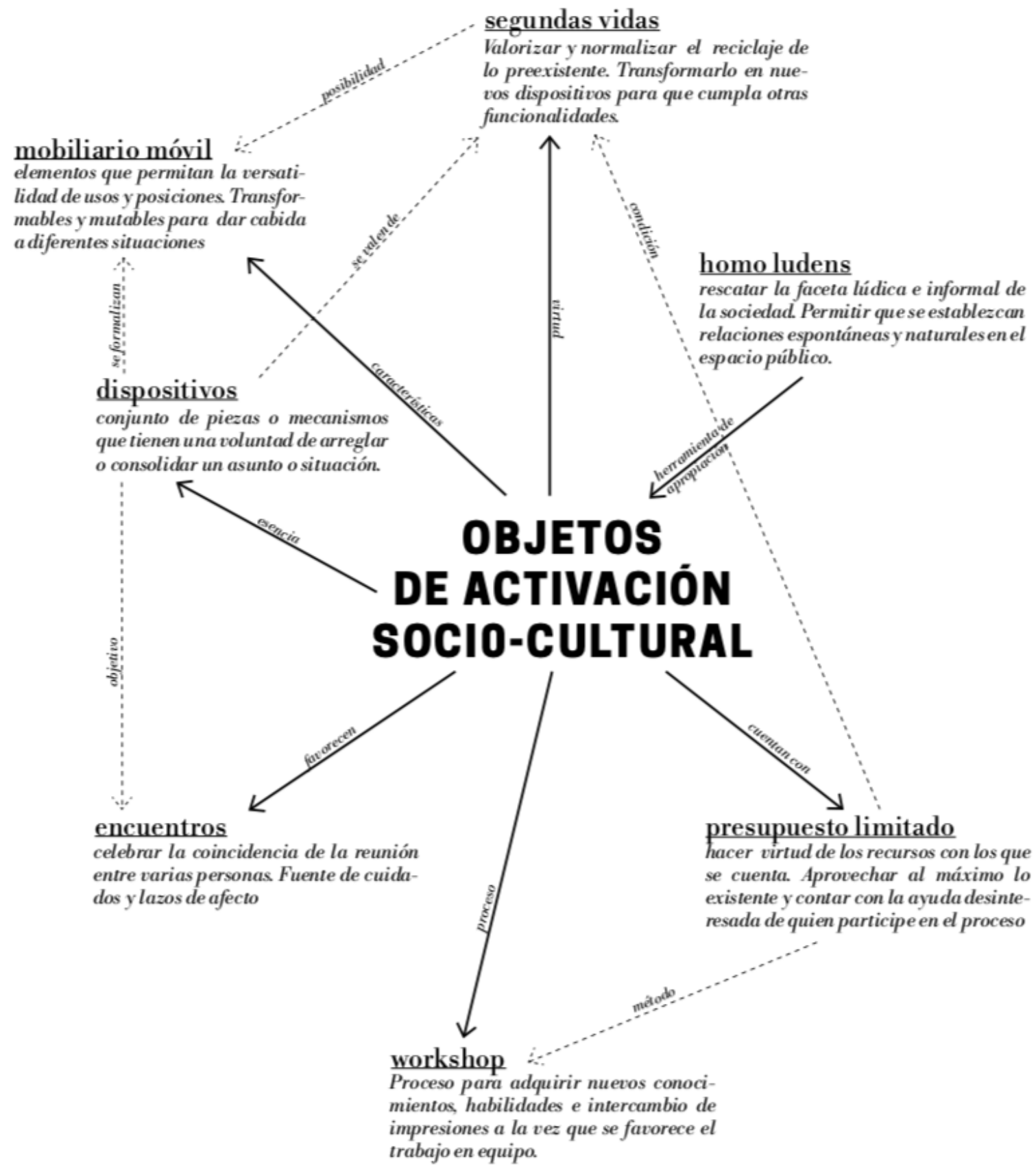


Resulta interesante el primer caso, Identidad, un pabellón de madera que divide la Plaça Nova en dos, recuperando la antigua plaza de 1714 y enseñando la evolución del arco romano a la bóveda catalana. El aporte urbano de este proyecto se basa en generar un nuevo punto de encuentro en la ciudad activado, dotando de un uso concreto a un espacio sobredimensionado como es el de la plaza Nova.
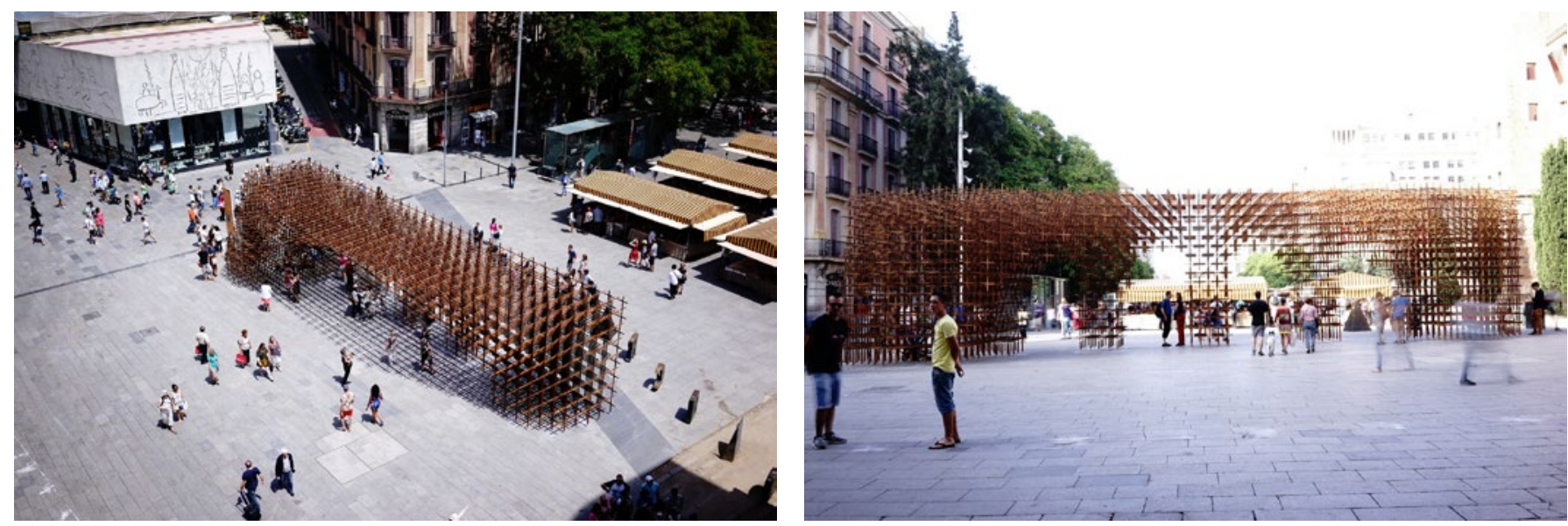

Imágenes 25 y 26. Imágenes de BCN Re.Set Identidad, de Urbanus y los alumnos de arquitectura de la Universidad La Salle (2014. Barcelona). Fuente: https://www. plataformaarquitectura.cl/cl/626922/bcn-r-et-identidad-urbanus

En la misma línea se desarrolla un proyecto \#estaesmiplaza. Se trata de un objeto hinchable que permite desarrollar una secuencia de acciones que pretenden fomentar la utilización del espacio público para los vecinos y la infancia. La membrana plástica de la estructura sirve como soporte para acoger intervenciones colectivas a través de dibujos, composiciones y escritos para incentivar la libertad de expresión y la imaginación. El dispositivo sirve para activar un espacio dentro de la plaza de Callao y permitir usos nuevos, ya que comúnmente son grandes zonas de tránsito únicamente.
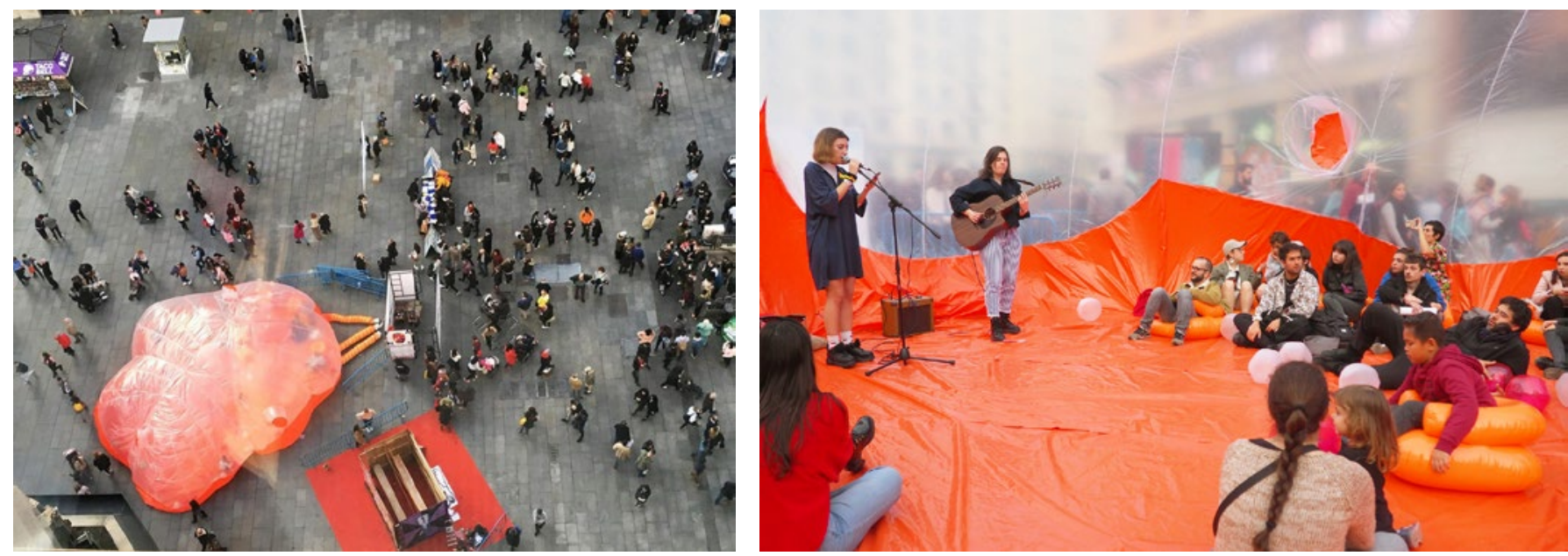

Imágenes 27 y 28. Imágenes de \#estaesmiplaza, de Conjuntos Empáticos (2019. Madrid). Fuente: https://www.plataformaarquitectura.cl/cl/935044/intervencion-esta-es-mi-plaza-conjuntos-empaticos

En la misma línea destaca el proyecto Mar de plástico, una iniciativa cultural en el marco de la Sens Arts Week, organizada por la Fundación Luis Seoane con motivo de la Semana Internacional de la Educación de La Coruña. Esta actividad puso a bailar en la plaza de María Pita, en La Coruña, a profesores, artistas y alumnos dentro de "Zaborra puztu/Infla tu basura", una iniciativa que consiste en habilitar un fondo disponible de estructuras inflables realizadas a partir de materiales plásticos. El proyecto implicó a una 
red de centros escolares de España, que trabajan colaborativamente desde el concepto de eco-justicia, reutilización, bio-ecología y conciencia medioambiental. La bondad de la iniciativa radica en crear, a través de la visualización del exceso de plástico, arquitecturas lúdicas como instalaciones artísticas que se apropien del espacio público.
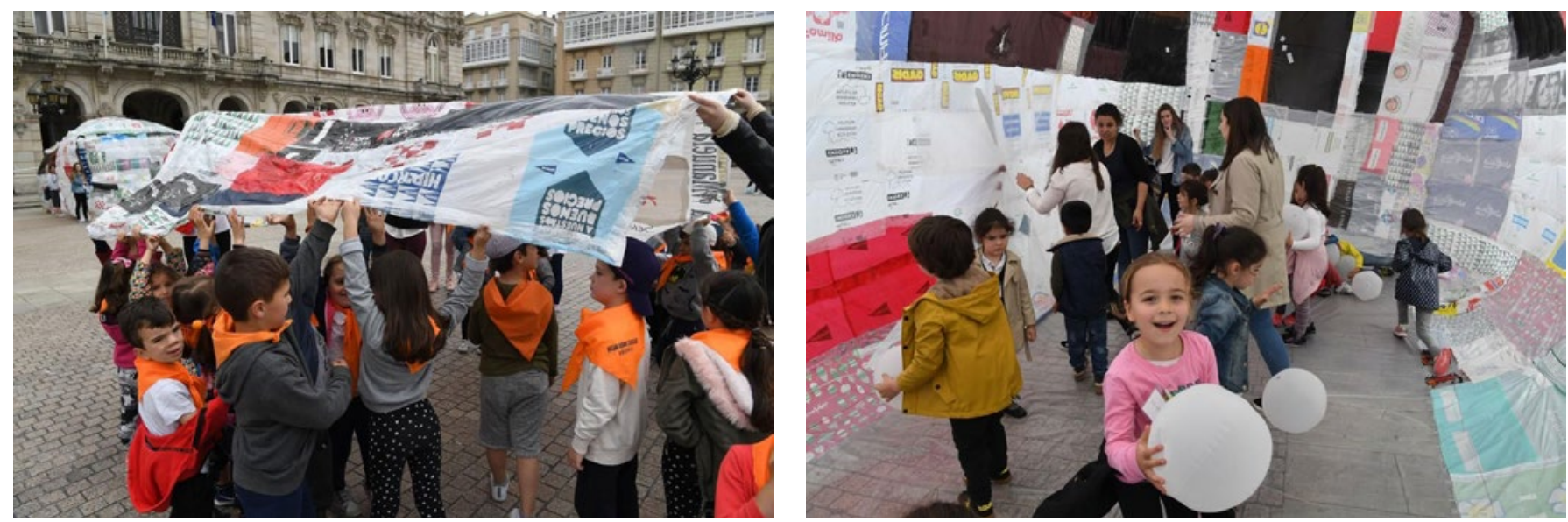

Imágenes 29 y 30. Imágenes de Mar de Plástico, desarrollado por los colectivos Basurama y Arropaineko Arragua y la participación del alumnado y maestras de infantil de los CEIP Ramón de la Sagra, CEIP Wenceslao Fernández Flórez, CEIP Rosalía de Castro y CEIP Emilia Pardo Bazán (2018. A Coruña). Fuente: https://www.laopinioncoruna.es/coruna/2018/05/30/arte-motor-educar-24047993.html

Por último, cabe mencionar el proyecto Todo Sobre Ruedas. Se trata de una propuesta de intervención en el espacio público que introduce una serie de mobiliarios móviles reciclados, provocando otros nuevos usos más allá de los cotidianos (jugar, leer, permanecer, tomar el sol, descansar...), como carreras de sofás, partidos de baloncesto sobre sillas de salón o un siestódromo móvil. Esta acción permite dotar a la ciudadanía pro-activa de las herramientas necesarias para apropiarse del espacio público. Los objetos permitieron activar la plaza por parte de usuarios que normalmente no habitaban en ella, a la vez que generaban interacciones insospechadas y espontáneas.
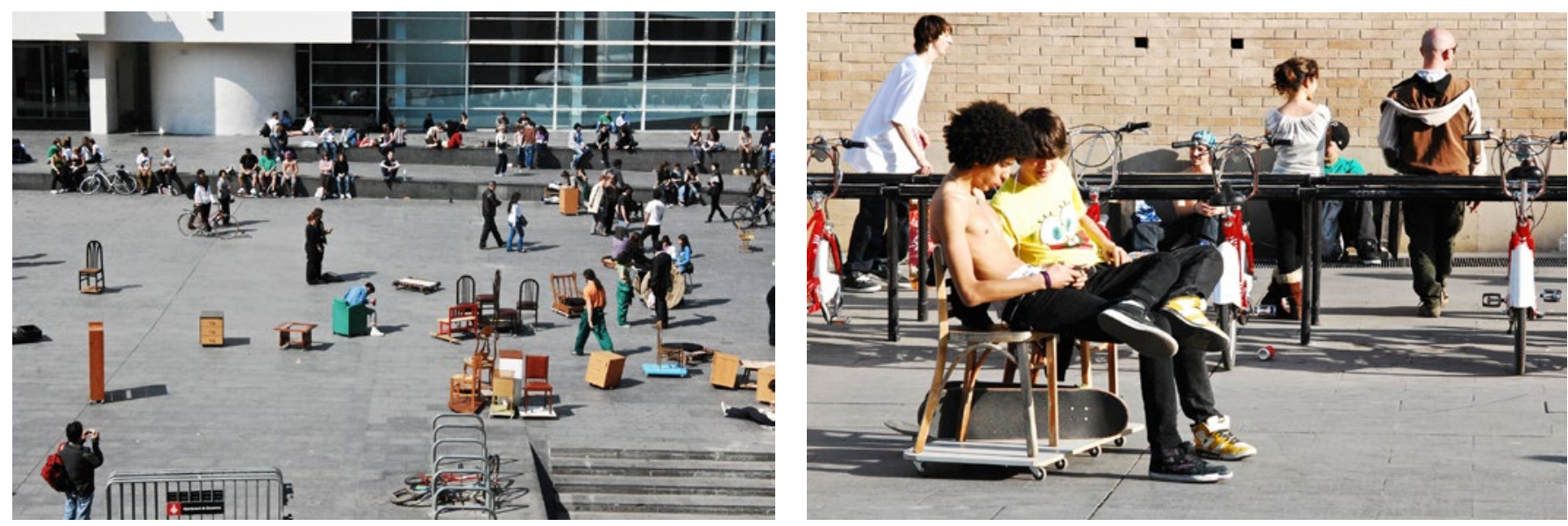

Imágenes 31 y 32. Imágenes de Todo sobre ruedas, de Basurama y Makea tu Vida (2009. Barcelona). Fuente: https://basurama.org/proyecto/todo-sobre-ruedas/

Las prácticas de hackeo urbano en su faceta física también juegan a nuestro favor. Se consideran activadoras del espacio urbano público, ya que fomentan el resurgir de eventos inesperados en lugares que no estaban diseñados para ello, ya sea porque se consideraban zonas de paso, lugares abandonados, infraestructuras infrautilizadas o áreas degradadas. Estas se hackean transformándolas en usos deportivos, espacios de juego infantil, cines, espacios de exhibición artística, de reunión o espacios de protesta y manifestación. 


\section{CONCLUSIONES}

El hackeo urbano, como alternativa y posibilidad dentro de la práctica artística y educativa, tiene una serie de virtudes que hacen de los proyectos algo más que meros objetos para el beneficio económico o especulativo. Los casos de estudio reflejados en este artículo se valen de una serie de bondades que tienen una voluntad clara de mejora de las ciudades, no solo en la dimensión física sino también en el tejido sociocultural. Virtudes como el hecho de mediar entre ciudad y sociedad, activar espacios degradados o sin uso, darle segundas vidas a objetos obsoletos, crear redes de cuidado entre comunidades, hacen que la ciudadanía adquiera la noción de pertenencia al espacio público. Por ello, es importante que se sigan promocionando desde las administraciones públicas iniciativas y políticas comunitarias que las fomenten y destinar más recursos económicos para que los colectivos y agentes que intervienen vean dignificada su labor.

También sería interesante observar cuál sería la situación de estas acciones si se normalizasen los procesos y se incluyeran en la práctica habitual de estudios y colectivos. Es decir, en todos los casos de interés de este artículo se observa una voluntad personal de sus autores para llevar a cabo el proyecto, con recursos en muchas ocasiones reducidos o inexistentes, pero qué pasaría si se estandarizasen este tipo de prácticas y en los grandes estudios de arquitectura llegasen encargos para "activar un solar abandonado en colaboración con los vecinos". Creo que la respuesta no está tanto en que este tipo de prácticas se estandaricen, sino en verlas como una opción más dentro de la disciplina y que ello facilite los temas legales y burocráticos para llevarlas a cabo.

Al final, la intención de esta investigación no niega la existencia o validez de una práctica artística o arquitectónica más ortodoxa, relacionada con el hecho constructivo. Pero sí defiende la existencia de ambas, ya que sólo con la primera se detectan muchas necesidades urbanas que deben encontrar respuesta y esta puede residir en normalizar el hackeo urbano como una práctica más dentro de la disciplina artística.

\section{REFERENCIAS BIBLIOGRÁFICAS}

Baraona, Ethel (2011). Hackeando el Espacio Social de los Encuentros. Revista Arquine \#58 | Dossier "Arquitectura y Activismo", pp. 1-4.

Baraona, Ethel y González, Paco (2013). Hacking the city. Conferencia en el marco de las jornadas Ciudad Sensible, organizadas por el colectivo Carpe Via, en la UPV. [en línea]. [Consulta: Noviembre 2020]. Disponible en: https://www.youtube.com/watch?v=jJxBfLVI6G0\&itct=CA0QpDAYAilTCMvigquw99ICFQtzTgodlkwJ5jIGcmVsbWZ1SM3h3sqz54uKPA\%3D\%3D\&gl=US\&hl=e n\&client=mv-google\&app=desktop

Bartlebooth (2016). La producción: Cuatro estrategias menores. A Coruña y Madrid: Bartlebooth.

Calvillo, Nerea y Mesa, Miguel (2018). Tender infrastructures: diseñando con cuidado, o aportaciones entre los "asuntos de los cuidados" y la arquitectura. Diseña (12), 172-195. Doi: 10.7764/disena.12, pp. 172-195.

Colmenares, Silvia (2016). TAME AND RECLAIM: domestic performances as a model for appropriation of the public space. EURAU 2016. European Symposium on Re- search in Architecture and Urban Design: In Between Scales. Ion Mincu University of Architecture and Urbanism. Bucarest. Rumania. 28-30 Septiembre 2016.

Di Siena, Domenico (2009). Espacios Sensibles. Hibridación físico-digital para la revitalización de los espacios públicos [en línea]. Tesis doctoral, Programa de Doctorado del Departamento de Urbanística y Ordenación del Territorio. Escuela Técnica Superior de Arquitectura de Madrid. [Consulta: Noviembre 2020]. Disponible en: http://urbanohumano.org/download/Espacios Sensibles 15.09.09.pdf 
Estalella, Adolfo (2016). Componer las ciudades. Instrucciones de uso para un urbanismo de vecindad. [i2] : Innovación e Investigación en Arquitectura y Territorio, Vol. 4 n. 2, pp. 1-5. ISSN 2341-0515.

Fossatti, Mariana (2011). El arte de hackear la ciudad. Ártica [en línea]. [Consulta: Noviembre 2020]. Disponible en: https://www.articaonline.com/2011/11/el-arte-de-hackear-la-ciudad/

Freire, Juan. (2009). Urbanismo emergente: ciudad, tecnología e innovación social. Paisajes Domésticos, Vol. 4 Redes de Borde, pp. 18-27.

Gómez, Alicia (2015). Sistemas urbanos emergentes: procesos informales de gestión y producción de espacio público [en línea]. Tesis doctoral, Programa de Doctorado del Departamento de Urbanística y Ordenación del Territorio. Escuela Técnica Superior de Arquitectura de Madrid. [Consulta: Noviembre 2020]. Disponible en: http://oa.upm. es/40081/1/ALICIA GOMEZ NIETO.pdf

Harvey, David (2013). Ciudades rebeldes. Del derecho a la ciudad a la revolución urbana. Madrid: Akal.

Himanen, Pekka (2002). La ética hacker y el espíritu de la era de la información. BarceIona: Madrid Destino.

Jacobs, Jane (1961). Muerte y vida de las grandes ciudades. Madrid: Capitán Swing.

Lefebvre, Henri (1968). El derecho a la ciudad. Madrid: Capitán Swing.

Mesías-Lema, Jose María (2019). Educación artística sensible. Cartografía Contemporánea para arteducadores. Barcelona: Graó.

Nebot, Nuria; González, Miguel y Fernández, Raúl (2014). Pensar la ciudad, nuevas herramientas para la regeneración urbana. Málaga: Área de Participación Ciudadana, Inmigración y Cooperación al Desarrollo del Ayuntamiento de Málaga.

Trachana, Angelique (2013). La ciudad sensible. Paradigmas emergentes de espacios informales y usos alternativos del espacio urbano. Urban, n. 5, pp. 97-111. ISSN 11380810. 
Juan Francisco Fuentes-Lojo. Arquitecto e investigador titulado por la Universitat Ramón Llull de Barcelona y máster en Comunicación Arquitectónica por la Universidad Politécnica de Madrid. Ha desarrollado su experiencia profesional en varios estudios de Barcelona y ahora compagina su faceta como arquitecto freelance, especializado en comunicación, con la de redactor cultural para varios medios y revistas.

kfuenteslojo@gmail.com 